trating Savart's observations on the action of sound on a jet of water. Dr. J. H. Gladstone exhibited some photographs of fluorescent substances. Bottles containing fluorescent liquids, such as æsculin or quinine di-sulphate, appear in the photographs nearly as black as a bottle filled with ink ; similarly, labels written with such liquids, although the characters are ordinarily invisible to the eye, show up their designs when photographed. In this room were to be seen also photographs of the Naples Aquarium, exhibited by Mr. W. A. Lloyd, and one of Dr. Dohrn's Zoological Station at Naples, lent by Mr. Darwin ; likewise some lithographed plates of recent Foraminifera from the Abrolhos Bank, exhibited by Profs. W. K. Parker and Rupert Jones. Mr. J. Norman Lockyer exhibited a series of photographs of metallic and solar spectra enlarged by Messrs. Negretti and Zambra from photographs taken by his new method of comparing spectra by means of a perforated shutter sliding in front of the slit of the spectroscope. In this room the new sextant devised by Capt. J. E. Davis was exhibited. This instrument, which will be found particularly useful in night observations, permits the taking of a series of observations without reading off each observation; this being accomplished by the adaptation of a micrometer novement to the tangent-screw, and the application of indicators to the arc of the instrument. Mr. Alfred Tribe here exhibited some specimens of metals (palladium, copper, \&rc.) which had become agglomerated in a most remarkable manner by hydrogenisation; under ordinary circumstances the metals shown existed in the form of fine powders, but, as soon as charged with hydrogen, become agglomerated.

The fifth room, or Principal Library, is by far the largest apartment of the suite. Mr. C. V. Walker's electrical apparatus for carrying out the "block system," or "space intervals," between trains on the South-Eastern Railway, was here displayed. Messrs. Tisley and Spiller exhibited their compound pendulum apparatus in action, and distributed cards with the exquisite curves described upon them. This firm exhibited also the beautiful triple combination double-image prism belonging to Mr. Spottiswoode, Mr. E. B. Tylor's ingenious apparatus for illus. trating refraction (already described in these columns) was exhibited in this room.* We observed also some splendid gold crystals exhibited by Mr. W. C. Roberts, Chemist to the Mint ; Mr. W. H. Barlow's "Logograph," a recording instrument for showing the pneumatic action accompanying the exercise of the human voice; and a pair of gyrostals exhibited by Prof. Sir William Thomson. Messrs. Negretti and Zambra exhibited their ingenious thermometer for recording deep-sea and atmospheric temperatures, already described in NATURE. Mr. John Browning exhibited a good collection of apparatus. Mr. G. P. Bidder's micrometer, a most ingenious device for observing the transit of very faint stars, in which the spider lines, capable of the usual micrometer movements, are illuminated by a side light, and are reflected into the eye-piece by a mirror, thus appearing bright upon a dark ground, and by interposing coloured glasses between the lamp and the spider lines can be coloured at pleasure. Sir Charles Wheatstone's new photometer is well worthy of notice: the screen slides along the divided scale and its motion causes the increased overlapping of two sliding wedges of neutral-tint glass. The light is looked at directly through a hole in the screen, and the latter moved along the scale till the light just ceases to be visible. We noticed also a micro-spectroscope of very good definition, showing the absorption spectrum of cantharides. Mr. Apps exhibited a model and diagram of a fireproof building, and a model of an improved apparatus for indicating the speed of revolving shafts, both being the inventions of Sir David Salomons.

* We should recommend lecturers using this apparatus to see that the wood is well seasoned; the one exhibited soon ceased to act satisfactorily, owing to the warping of the board.
The plan for rendering buildings fireproof consists in laying on water-pipes between the walls and floors of the building, these pipes being self-acting by means of fusiblemetal plugs or electrical communications. The lastnamed model is an application of the ordinary governor balls, which are connected with the shaft, and by a system of levers, with an index, which moves up a graduated scale. A double-action spectroscope with a divided object-glass, made by Grubb, of Dublin, was shown and explained by Lord Lindsay ; this instrument is intended by its owner to be attached to a large equatorial for the observation of stellar spectra. Among other noticeable things in this room we may mention the Megohm, one million British Association units, by Messrs. Elliott Brothers; Mr. George Barnard's highly artistic watercolour drawings and the copies of sacred Icons of the Greek Church in Russia, and photographs by Mr. John Leighton. Col. Stuart Wortley's photographs from life are high examples of art, and the group of living corals (Astroides calicula) from the Bay of Naples, exhibited by the Crystal Palace Aquarium Company, attracted large numbers of admirers by their beauty. At ro o'clock Dr. R. Norris, of Birmingham, exhibited in the meeting-room experiments to illustrate a form of contractive energy which displays itself in various substances. Among other things the Doctor showed that the statement that indiarubber contracts by heat is incorrect; this substance, it is true, contracts in the direction of its length, but it expands in breadth at the same time, thus resembling the so-called contraction of muscular fibre.

In soirées of this kind experiments illustrative of new chemical discoveries are generally "conspicuous by their absence." This surely cannot be due to the fact that the science does not permit of public demonstration; it arises rather from the "messy" nature of the materials employed by chemists, thus precluding the introduction of chemicals into such rooms as are devoted by the Society to their gatherings. We are of opinion that in not fitting up and adding to their now noble apartments a laboratory, an omission has been made which may be regretted in the future.

\section{THE LECTURES AT THE ZOOLOGICAL SOCIETY'S GARDENS}

II.

$\mathrm{N}$ the second and third of his lectures On the Geugraphical Distribution of the Mammalia, delivered on the Tuesday and Friday of last week, Mr. Sclater described in detail the ranges of the different orders of terrestrial mammals ; and to avoid unnecessary repetition, employed the well-known system of division of the earth's surface, proposed before the Linnean Society in 1857 , from a study of the bird class, according to which there are six regions-(I) The Palaarctic, including Europe, Africa north of the Atlas Mountains, and Northern Asia. (2) The Etriopian, including all Africa south of the Atlas Mountains, and the southern part of Arabia. (3) The Indian, including Asia south of the Himalayas, Southern China, and the Indian Archipelago. (4) The Australian, including Australasia. (5) The Nearctic, including North America down to the centre of Mexico; and (6) The Neotropical, including South and Central America. The following is a summary of his remarks.

Among the monkeys the anthropoid apes inhabit equatorial Africa, where the gorilla and chimpanzee are found; Sumatra and Borneo are the home of the orang outang; while the eastern portion of India, Burmah, and the Indian Archipelago constitute the habitat of the various species of gibbon. The catarrhine monkeys, including the green monkeys (Cercopithei i), and the macaques inhabit Africa and India respectively; the latter, however, extending into Africa north of the Sahara, as far as Apes Hill and the Rock of Gibraltar. The platyrrhine monkeys, among 
which are the spider monkeys, the howlers, and the marmosets, are found in the Neotropical region, except in its southern and western parts. The lemurs are mostly confined to the island of Madagascar, some few inhabiting Eastern India, and two forms occurring in Western Africa.

Among the large order of the Carnivora the lion is a denizen of the forests of the Ethiopian region, and spreads slightly beyond it into India. The tiger is found in the Indian region, and spreads up into China and Central Asia, where its coat becomes coarser in texture. The leopard is distributed over the districts of the lion and tiger; it is also found in Borneo and Ceylon, whilst the lynx occurs in the Neartic and Palaarctic regions. The dogs are cosmopolitan, though it is doubtful whether the single form of Australia has not been introduced by man in early times. The bears inhabit the Palæarctic, the Nearctic, and the Indian regions, being also found in the Andes of Peru.

Among the odd-toed, or Perissodactylate Ungulates, the horses and asses are strictly Old-World forms, the exact place of origin of the former being uncertain. The asses are spread over the Indian and Ethiopian regions. The tapir is very aberrant in its distribution, one species appearing only in Sumatra and the Malay Peninsula, while in the northern portion of South America and Central America three others occur. The rhinoceroses are from the Indian and Ethiopian regions only, the Asiatic species all being now or having lately been exhibited in the Zoological Gardens. Those from Africa are less perfectly known, only two species having been accurately determined.

Among the even-toed, or Artiodactylate Ungulates, the camels are very peculiar in their habitats, the Llamas of the Andes and the camels of Africa, Arabia, and part of Russian Asia being the only known forms; those from the last-named locality being the only known wild true camels of the present day. The giraffe is purely Ethiopian. The bison in North America represents the oxen of the Indian region, which in Africa and Arabia are in great measure replaced by the antelopes, so varied in form and size. The Cervidæ are not found in the Ethiopian nor Australian regions. The hippopotamus inhabits all the large rivers of Africa, the smaller species being found in and about Liberia. Of the Swine-family the peccaries are the representatives in the Neotropical region, whilst the quaint Wart-Hog and Red River $\mathrm{Hog}$ are exclusively African.

The hyrax, or coney of Scripture, whose zoological position is so uncertain, is found in Arabia and parts of Africa only.

There are only two species of elephant known, the Indian being from the Indian region, and the African from the Ethiopian. In very recent times they abounded in Siberia, and earlier still in many other parts of the world.

The Neotropical region abounds in peculiar Edentate animals, as the armadillos, sloths, and ant-eaters. The scaly ant eaters or Pangolins, and the ant-bears or Orycteropus, are found, the former in India and Africa, the latter in Africa only.

Among the Insectivora, the peculiar Solenodon inhabits St. Domingo; the, gilded mole, South Africa; the Tenrec, Madagascar; and the Tupaias, the Malay districts.

Among the Rodentia the porcupines, divided into two well-distinguished sub-families, inhabit, one the Old and the other the New World. The Neotropical region, however, is the head-quarters of the Hystricida; the capybara, together with the agoutis, and numerous other forms being from that locality. There are also found the chinchilla and viscacha. The beaver abounds in the Nearctic region, and used to do so in Europe, till the increase of population has almost exterminated it. The hare and rabbits have a wider distribution, as have also the squirrels.

It will be noticed that Australia has been scarcely men. tioned in the above remarks, and that the dog which is spoken of in connection with it is not known certainly to be indigenous. This is because the mammalian fauna is almost entirely represented by animals of the Marsupial order, the kangaroos, bandicoots, phalangers, wombat, koala, thylacine, and dasyures being peculiar to it and Van Dieman's land. Among Marsupialia the group of opossums is only found in the Neotropical region, extending quite through Mexico into the United States.

The Monotremata, including only the duck-bill or ornithorhynchus and the echidna, are confined to New South Wales and Tasmania.

\section{(To be continued.)}

\section{THE FLUCTUATIONS OF THE AMERICAN LAKES AND THE DEVELOPMENT OF SUN-SPOTS}

$\mathrm{I}$ the course of an investigation, undertaken in my capacity as Geologist to the B.N.A. Boundary Commission, as to late changes of level in the Lake of the Woods, bearing on the accuracy of certain former sur veys, I found it desirable to tabulate the better-known fluctuations of the great lakes for a series of years as a term of comparison. The observations of secular change in Lake Erie are the most complete, and these, when plotted out to scale, showed a series of well-marked undulations which suggested the possibility of a connection with the eleven-yearly period of sun-spot maxima. A comparison with Mr. Carrington's diagram of the latter confirmed this idea, and as I do not remember to have seen these phenomena connected previously, I have been induced to draw out the reduction of both curves here presented, and the table of the height of water in the lakes.

The changes of level affecting the great lakes are classed as follows by Colonel Whittlesey, who has given much attention to the subject :-

I. General rise and fall, extending through a period of many years, which may be called the "Secular Variation."

2. Annual rise and fall within certain limits, the period of which is completed in about twelve months.

3. A sudden, frequent, but irregular movement varying from a few inches to several feet. This is of two kinds, one due to obvious causes, such as winds and storms; another, described as a slow pendulum-like oscillation, has been somewhat fully discussed by Whittlesey in a paper read before the American Association at its last meeting, and is due probably to barometric changes in the superincumbent atmosphere.

The first class is the only one directly included in the present inquiry.

I.-Table of Great Lakes.--In Mr. Lockyer's new work on Solar Physics, chap. xxvi., entitled "The Meteorology of the Future," exhibits the parallelism of periods of solar energy, as denoted by the outburst of sun-spots, with the maximum periods of rainfall and cyclones, and for the southern hemisphere, by a discussion of his own and Mr. Meldrum's results. In the table (p. 505) I have arranged the more accurate numerical observations of the height of the lakes from registers kept for the last few years, in a method similar to that there adopted.

Prof. Kingston's observations of Lake Ontario were taken at Toronto, and measured upward from an arbitraxy mark. They extend from the year 1854 to 1869 , and inciude the minimum periods of 1856 and 1867 , and the maximum of 1860 . Taking the mean anrual level for 